\title{
Congenital short bowel syndrome
}

INSERM

\section{Source}

INSERM. (1999). Orphanet: an online rare disease and orphan drug data base. Congenital short bowel syndrome. ORPHA:2301

Congenital short bowel syndrome is a rare intestinal disorder of neonates of unknown etiology. Patients are born with a short small bowel (less than $75 \mathrm{~cm}$ in length) that compromises proper intestinal absorption and leads chronic diarrhea, vomiting and failure to thrive. 